\title{
Processos de individuação dos torcedores na Arena do Grêmio
}

\author{
Selfhood Processes of the Football Fans at the Arena do Grêmio
}

\author{
Gustavo Andrada Bandeira \\ Universidade Federal do Rio Grande do Sul, Porto Alegre/RS, Brasil \\ Doutor em Educação, UFGRS \\ Fernando Seffner \\ Universidade Federal do Rio Grande do Sul, Porto Alegre/RS, Brasil \\ Doutor em Educação, UFRGS
}

\begin{abstract}
RESUMO: Neste trabalho focamos nosso olhar sobre como os torcedores do Grêmio foram interpelados por diferentes conteúdos ao realizarem um trânsito entre o antigo estádio Olímpico Monumental e a atual Arena do Grêmio, especialmente na relação que se estabelece entre um sujeito individual, torcedor, e o sujeito coletivo, torcida. Para a construção de nosso material empírico realizamos diálogos com pequenos grupos de torcedores antes de partidas realizadas no novo estádio gremista. A tecnologia da Arena do Grêmio permite individualizar as ações dos torcedores por seus mecanismos de controle, o que poderia autorizar que o coletivo de torcedores fosse desfeito a qualquer momento. A torcida, em algumas circunstâncias, não poderia ser responsabilizada por ações realizadas por individualidades torcedoras, ao mesmo tempo em que as individualidades torcedoras não poderiam ser adequadamente avaliadas em suas ações sem levar o contexto da torcida em consideração.
\end{abstract}

PALAVRAS-CHAVE: Torcedor; Torcida; Arena; Estádios.

ABSTRACT: The article analyzes how the fans of Grêmio Foot-Ball Porto Alegrense were challenged by different issues when making the transit between the old Monumental Olympic stadium and the current Arena do Grêmio. The focus of the analysis is on the relationship established between an individual subject, supporter, and the collective subject, football crowd. The empirical material was produced from dialogues with small groups of fans before matches held at Arena do Grêmio. The technology of the Arena do Grêmio allows individualizing the actions of the fans by their control mechanisms, which could authorize the collective of fans to be undone at any time. The fans, in some circumstances, could not be held responsible for actions taken by supporters, while the supporters could not be adequately evaluated in their actions without taking into account the context of the supporters.

KEYWORD: Fan; Supporter; Arena; Stadiums. 


\section{INTRODUÇÃo ${ }^{1}$}

Os estádios de futebol inserem os sujeitos em diferentes pedagogias. Eles são espaços de vivência intensa dos diferentes conteúdos produzidos sobre gênero, raça, geração, sexualidade, nacionalidade, corpo, pertenças políticas, emoções e sobre o torcer. 0 futebol, como qualquer prática cultural, está sempre envolvido em disputa por significados, ele é uma rede complexa em que diferentes atores transitam por diferentes funções. Sendo um esporte moderno, o futebol pode ser lido como uma instituição, complementar a tantas outras como a escola e a família. Os esportes “[...] representam e recriam a moderna domesticação das emoções, funcionando como pedagogias acerca de formas específicas de autocontrole. [...] São também concebidos, de certo modo, como os espaços controlados nos quais podem, contidamente, serem exteriorizadas as emoções". ${ }^{2}$

O futebol faz circular diferentes emoções, aproximando e distanciando sujeitos. Algumas unidades e afetos, inclusive políticos, produzidos nos estádios de futebol ou durante as partidas não serão mantidos, necessariamente, ao final dos jogos ou em outros contextos. $\mathrm{O}$ estádio de futebol possui um histórico de registros simbólicos e de particularidade de relações que autoriza algumas práticas, que permitem aos sujeitos entenderem esse espaço como autônomo em relação aos demais espaços cotidianos. As linhas de continuidade ou ruptura entre o que se faz no estádio e o que se faz fora dele são contingentes e de complexos caminhos.

Normativas vindas da FIFA, das confederações continentais e de federações nacionais têm colocado em questão práticas historicamente autorizadas nos estádios de futebol, em sintonia com modificações no âmbito da cultura e impactos do campo dos direitos humanos. A modernização dos espaços do torcer, que vem ganhando andamento no Brasil, especialmente, a partir da década de 1990, foi catalisada com a realização da Copa do Mundo de futebol masculino no Brasil, em

\footnotetext{
${ }^{1}$ Este artigo é um dos produtos do projeto de pesquisa "Estratégias pedagógicas de construção, manutenção e modificação das masculinidades: ensinando a ser torcedor e a ser homem nas arenas de futebol pós Copa do Mundo", Processo: 400749/2016-5, Chamada Universal 01/2016 CNPq.

${ }^{2}$ GUEDES. Os "europeus" do futebol brasileiro ou como a "pátria de chuteiras" enfrenta a ameaça do mercado, p. 75-76.
} 
2014. Com isso, diferentes olhares foram colocados para os estádios, os torcedores e suas práticas.

Dentro das diferentes disputas por significados sobre as práticas torcedoras nos estádios, envolvendo diretamente a torcida do Grêmio Foot-Ball Porto Alegrense - clube no qual realizamos nosso trabalho de campo -, foi possível constatar certo 'retorno' da Coligay na memória coletiva de seus torcedores. A Coligay reuniu entre o final da década de 1970 e o início dos anos 1980 um grupo de torcedores identificados como homossexuais que realizaram variadas performances no estádio Olímpico e, também, em outros estádios do Rio Grande do Sul. 0 que chamamos de retorno da Coligay se dá não apenas pelos materiais que passaram a ser produzidos sobre ela: um livro, ${ }^{3}$ um média-metragem ${ }^{4}$ e uma tese de doutorado, 5 mas, especialmente, por sua presença no Memorial Hermínio Bittencourt, na Arena do Grêmio, inaugurado em princípios de 2016.

Além desse 'retorno' da torcida homossexual, agora inserida na linha do tempo da história do clube, procuramos olhar como as manifestações dos torcedores na Arena se configuravam a partir da nova arquitetura do estádio e das interdições as manifestações que apareceram, especialmente após o 'caso Aranha', episódio em que o, então, goleiro do Santos, Aranha, foi chamado de macaco por torcedores do Grêmio em partida pela Copa do Brasil de 2014. ${ }^{6}$ Em função das ofensas raciais, o Grêmio acabou sendo eliminado da competição e ampliou os debates sobre o permitido e o proibido de ser manifestado nos estádios de futebol.

Queríamos tentar visualizar, também, como se dariam algumas das disputas entre o que era esperado do público e o que esse público esperava do novo estádio. Continuaria sendo possível apontar para sujeitos coletivos, para o ator social, 'torcida do Grêmio' nesse novo contexto, em que as variáveis de espaço e de tempo experimentaram modificação? Vale lembrar que o clube não apenas reformou seu estádio, mas, edificou um estádio totalmente novo, mudando geograficamente de local dentro do município de Porto Alegre, e entregando a antiga sede. É nesse

\footnotetext{
${ }^{3}$ GERCHMANN. Coligay: tricolor e de todas as cores.

${ }^{4}$ Para o que der e vier dirigido e roteirizado por Pedro Guindani

${ }^{5}$ ANJOS. De "são bichas, mas são nossas" à "diversidade da alegria": uma história da torcida Coligay.

${ }^{6}$ BANDEIRA; SEFFNER. Aranha, macaco e veado: o legítimo e o não legítimo no zoológico linguístico nos estádios de futebol.
} 
trânsito, especificamente na torcida do Grêmio, em que se poderia esperar uma sociabilidade torcedora diferente, que pretendemos olhar de que maneira os torcedores dialogam com esse novo espaço e nesse novo tempo, com discursividades em disputas por legitimidade. 0 objetivo deste trabalho foi procurar pensar como o currículo do torcer faz uma aproximação e distanciamento da relação do indivíduo torcedor com o sujeito coletivo torcida a partir de conteúdos que apareceram ou que passaram a ser questionados no contexto dos estádios de futebol. Para atingir nosso objetivo, este trabalho está dividido em seis partes. Após essa breve introdução, discutiremos sobre nossas estratégias metodológicas. A terceira seção procura mostrar como ocorre a inscrição do sujeito individual torcedor na coletividade da torcida. $\mathrm{Na}$ sequência do texto apontamos como o exercício da memória da torcida homossexual pode ser distinto quando pensado no indivíduo torcedor ou na coletividade torcedora. A quinta parte de nosso trabalho aponta para as justificativas dos torcedores sobre a responsabilidade de indivíduos e/ou do coletivo no caso em que o goleiro Aranha foi ofendido racialmente. Finalizamos nosso artigo apontando alguns entendimentos que nos mostram um processo de individualização dos torcedores nesses primeiros anos de uso no novo estádio do Grêmio, indicando formas de apropriação do novo espaço de exercício do torcer.

\section{ESTRATÉGIAS DE JOGO: PEDAGOGIAS, DIÁLOGOS E INTERPELAÇÃO}

Os estádios de futebol se constituem como um artefato cultural, eles são produzidos, são feitos e são portadores de pedagogias. Os estádios são coisas concretas, não apenas porque são feitos de concreto, mas porque se constituem como artefatos portadores de pedagogias de gênero e de sexualidade, dentre outras pedagogias culturais. É necessário passar por diferentes processos de aprendizagens para que os sujeitos possam ser introduzidos nesse contexto cultural. "A prática e a contemplação esportiva podem ser consideradas atos 
educativos, sejam eles atinentes ao domínio das técnicas corporais, das sensibilidades estéticas ou dos controles/descontroles emocionais".7

Diferentes instâncias trabalham nos processos da construção dos sujeitos, "não é apenas a escola que educa [...] outras instâncias sociais também o fazem na medida em que constroem representações, subjetivam os indivíduos e grupos sociais". ${ }^{8}$ A partir dos Estudos Culturais, é possível entender que existe pedagogia em diferentes artefatos culturais. "As pedagogias culturais que são colocadas para funcionar através de artefatos culturais da mídia contemporânea, dentre outros, têm-se revelado, pois, como processos educativos potentes quando se trata de instituir relações entre corpo, gênero e sexualidade". ${ }^{9}$

Dentre as estratégias metodológicas que adotamos para a realização dessa investigação, estava um diálogo com pequenos grupos de torcedores, quase sempre duplas ou trios, nos quais nos inseríamos para discutir algumas das percepções desses indivíduos sobre a mudança do estádio Olímpico Monumental para a Arena do Grêmio, como entendiam o 'caso Aranha' e quais memórias possuíam sobre a extinta Coligay. Essas conversas foram realizadas, na maior parte das vezes, antes das partidas. Estávamos sempre vestidos com uma camiseta do Grêmio, nos apresentávamos enquanto pesquisadores, apontávamos brevemente os assuntos que gostaríamos de conversar e solicitávamos registrar esse diálogo em um gravador. Boa parte dos grupos abordados para os diálogos eram de torcedores que estavam tomando cerveja. Acreditávamos que essa era uma boa oportunidade de contexto de abordagem, não apenas por participarmos de um diálogo entre torcedores, como, também, pelo tempo que os torcedores precisariam ficar antes de subir até a esplanada ou entrar no estádio. Tendo em vista a proibição da comercialização de bebida alcoólica nas praças esportivas do Rio Grande do Sul, as cervejas compradas fora do estádio precisariam ser consumidas antes do acesso pelas rampas, assim como as adquiridas na esplanada não poderiam atravessar os portões.

\footnotetext{
${ }^{7}$ DAMO. Do dom à profissão: uma etnografia do futebol de espetáculo a partir da formação de jogadores no Brasil e na França, p. 43-44.

${ }^{8}$ FISCHER. Verdades em suspenso: Foucault e os perigos a enfrentar, p. 68-69.

${ }^{9}$ MEYER. Corpo, violência e educação: uma abordagem de gênero, p. 223.
} 
Com esses diálogos, foi possível tentar verificar como os torcedores produziam narrativas a partir de suas inserções e distintas apropriações nesse novo espaço, assim como eram interpelados pelo currículo de torcedor de futebol e de masculinidade atravessados pelos conteúdos que acabavam por mobilizar as condutas dos torcedores do Grêmio.

Uma interpelação é, pois, um chamamento, um enunciado que convoca o sujeito o qual pode ou não assumir a convocação. Seria como se alguém dissesse "ô baixinho" e o cara se virasse e respondesse: "Quem? Eu?", reconhecendo-se de algum modo naquela interpelação e assumindo-se como tal.10

A aposta por esses diálogos se deu a partir do entendimento de que as narrativas produzidas pelos sujeitos permitiriam acessar diferentes tentativas de dar inteligibilidade às práticas desenvolvidas por esses atores. Acabamos conversando com os chamados 'torcedores comuns'. Essa alcunha é recorrente entre os mediadores especializados para diferenciar os indivíduos que comparecem aos estádios de forma distinta das torcidas organizadas, e, especialmente, no caso dos torcedores do Grêmio, aqueles que não frequentam o setor da Geral. A "Geral do Grêmio", atualmente a maior torcida do clube, surgiu no início deste século influenciada pelas torcidas uruguaias e argentinas na forma de se portar nos estádios. A Geral inaugurou o movimento de 'barras' que ocupou outros estados brasileiros a partir da metade da última década e que serviu, de certa forma, como contraponto às torcidas organizadas que dominavam o cenário brasileiro quando dessa 'importação', no início deste século.

A vocação da torcida é o apoio incondicional ao clube, que se expressa no estádio através do incentivo agitando bandeiras e entoando cânticos, permanecendo de pé, durante todo o jogo, independente do placar. Os cânticos expressam de modo exemplar esta concepção assim como as faixas, e as barras, enquanto que, para as organizadas, a provocação, a rivalidade entre torcidas e a incitação ao confronto são elementos recorrentes. Aparentemente espontâneos, os cânticos estão submetidos a regras e técnicas, sendo cuidadosamente criados e obrigatoriamente exigidos.

\footnotetext{
${ }^{10}$ LOURO. Discursos de ódio, p. 271.
} 
Expressão obrigatória desse novo modelo de torcedor, cantar o tempo inteiro exige dedicação e disciplina. ${ }^{11}$

Esse diálogo, nesse espaço específico, foi pensado para provocar que os indivíduos se pensassem dentro de um sentimento de pertencimento ao coletivo de torcedores. Mais do que pensar nos indivíduos como pré-existentes às interações dos estádios, esses encontros rápidos nos permitiram acessar a forma como esses sujeitos torcedores e masculinos se entendiam interpelados pelos currículos de masculinidades e do torcer nos estádios de futebol, ${ }^{12}$ e de que forma dialogavam com a mudança de endereço do Grêmio. Esse diálogo, nesse espaço específico, foi pensado para provocar que os indivíduos se pensassem dentro de um sentimento de pertencimento ao coletivo de torcedores. Mesmo que as falas fossem individuais, elas não podem ser descontextualizadas dessa pertença:

[...] não existe nenhum "eu" que possa se separar totalmente das condições sociais de seu surgimento, nenhum "eu" que não esteja implicado em um conjunto de normas morais condicionadoras, que, por serem normas, têm um caráter social que excede um significado puramente pessoal ou idiossincrático. ${ }^{13}$

0 protagonismo das torcidas organizadas nas representações sobre o torcer pode gerar certa impressão de homogeneidade nas manifestações torcedoras nos estádios de futebol. Entretanto, muitas disputas por legitimidades acontecem, especialmente nos setores dos 'torcedores comuns'. Por mais que a torcida seja narrada, em diferentes oportunidades, como uma totalidade, dentro dela é possível visualizar uma série de diferenças, com algumas disputas bem marcadas.

\section{A INSCRIÇÃO NO SUJEITO COLETIVO TORCIDA}

Nos estádios de futebol, algumas práticas são autorizadas em um processo coletivo de construção de fraternidades e solidariedades masculinas. No estádio se está, ao mesmo tempo, em casa e no espaço público. Os palcos onde ocorrem os jogos

\footnotetext{
11 TEIXEIRA. Futebol, emoção e sociabilidade: narrativas de fundadores e lideranças dos movimentos populares de torcedores no Rio de Janeiro, p. 8.

${ }^{12}$ BANDEIRA. Uma história do torcer no presente: elitização, racismo e heterossexismo no currículo de masculinidade dos torcedores de futebol.

${ }^{13}$ BUTLER. Relatar a si mesmo: crítica da violência ética, p. 18.
} 
carregam e instauram representações importantes na cultura do futebol. Os estádios são entendidos como a 'casa' de seus respectivos clubes. Esse entendimento é produtivo para pensarmos nas produções de significados. Como lembra Roberto DaMatta, "sabemos e aprendemos muito cedo que certas coisas só podem ser feitas em casa e, mesmo assim, dentro de alguns de seus espaços". ${ }^{14}$

Com uma carga simbólica e afetiva importante, a construção de enfrentamentos verbais, como os que ocorrem nos estádios de futebol, possui com a coletividade e com seu tempo de duração uma relação destacada de produção de sentidos. Em alguma medida, separado da vida cotidiana

[...] activam-se sentimentos muito fortes, num quadro imaginário, e a sua manifestação aberta na companhia de muitas outras pessoas pode ser a mais agradável e libertadora de todas, porque na sociedade, de um modo geral, as pessoas estão mais isoladas e têm poucas oportunidades para manifestações colectivas de sentimentos intensos. ${ }^{15}$

Boa parte das manifestações que ocorrem nos estádios de futebol é protagonizada por um sujeito coletivo, 'torcida', "vale a pena distinguir o torcedor individual da torcida - um ser coletivo, nascido dos indivíduos, mas inexplicável se tomado como simples soma destes". ${ }^{16}$ Estar em uma torcida ou fazer parte de uma torcida permite uma série de inscrições. Essas inscrições provocam distintas incitações para a circulação de significados em uma determinada cultura.

Essa coletividade dos torcedores de futebol em uma torcida aparece em um contexto festivo. A festa permite borrar algumas fronteiras existentes, como as de público e privado. No estádio se está em casa e no espaço público ou não se está efetivamente em nenhum dos dois, mas em uma intersecção entre ambos. Rita Amaral comenta que nas festas existe uma diminuição da distância entre os indivíduos, o que permite a transgressão de algumas normas coletivas, potencializando a existência de uma "efervescência coletiva". ${ }^{17}$ As identidades individuais não são apagadas nas festas, e, nelas nem tudo é permitido, mas a ideia da festa permite pensar que as hierarquias do cotidiano sofrem deslocamentos,

\footnotetext{
${ }^{14}$ DAMATTA. A casa \& a rua: espaço, cidadania, mulher e morte no Brasil, p. 50.

${ }^{15}$ ELIAS. O processo civilizador II: formação do Estado e Civilização, p. 71-72.

${ }^{16}$ FAUSTO. De alma lavada e coração pulsante, p. 146.

${ }^{17}$ AMARAL. Festa como objeto e como conceito.
} 
fazendo com que ações desvalorizadas nos espaços 'sérios' da vida possam ser mais bem avaliadas nesse espaço.

Uma das formas de olhar para as manifestações dos torcedores em estádios de futebol é procurar observar qual o comportamento desse sujeito coletivo em multidão: 'torcida'. Aqui, não se entende a multidão como um todo unificado, ${ }^{18}$ mas como um conjunto de pessoas, um coletivo que autoriza determinados comportamentos ao mesmo tempo em que inibe uma série de outros. Olhar para a multidão implica procurar localizar quais as falas são possíveis; o que os sujeitos se autorizaram a gritar; quais gritos são rechaçados; como as manifestações individuais de torcedores receberam adesão ou não. As manifestações individuais são atravessadas por uma espécie de 'controle' produzido pela própria torcida que autoriza ou desautoriza as manifestações que ali aparecem.

\section{A AUTORIZAÇÃo dA MEMÓRIA DA COLIGAY PARA TORCIDAS E TORCEDORES}

Dentro do dispositivo pedagógico dos estádios de futebol, a Coligay acabou ocupando um lugar de destaque. Ela ocupou o lugar do apagamento, do desconhecimento, da ignorância.

Não se deve fazer uma divisão binária entre o que se diz e o que não se diz; é preciso tentar determinar as diferentes maneiras de não dizer, como são distribuídos os que podem e os que não podem falar, que tipo de discurso é autorizado ou que forma de discrição é exigida a uns e outros. ${ }^{19}$

Entretanto, nesse jogo de visibilidade e invisibilidade, a Coligay passou a disputar um novo lugar durante a segunda década deste século. No início de 2016, foi inaugurado, na Arena do Grêmio, o Memorial Hermínio Bittencourt. Além de bolas, uniformes e troféus, o memorial também conta com painéis em homenagem à torcida e aos torcedores. Um desses painéis é dedicado à Coligay. 0 painel é intitulado "Diversidade da Alegria" e apresenta o seguinte texto:

Na cinzenta década de 1970, o Brasil atravessava um dos períodos mais obscuros de sua história, com repressão e censura suprimindo e sufocando as liberdades democráticas. Era preciso ser muito corajoso

\footnotetext{
${ }^{18}$ RUDÉ. A multidão na história: estudo dos movimentos populares na França e na Inglaterra 1730-1848.

${ }^{19}$ FOUCAULT. Vigiar e punir: nascimento da prisão, p. 30.
} 
para expor sua preferência sexual, ainda mais dentro de um estádio de futebol. Mas a torcida Coligay encarou a ditadura e tomou para si o desafio de reerguer o moral do time, que andava para baixo. Vestindo figurino extravagante e ousado de túnicas esvoaçantes, plumas e paetês - tudo em azul, preto e branco, é claro - cerca de 60 rapazes gremistas provaram que o Grêmio é mesmo um clube plural e inovador do país.

Volmar Santos, então gerente da célebre boate Coliseu, de Porto Alegre, foi quem organizou a festa: "Eu queria a torcida incentivando mesmo quando o time não ia bem... Quando parti pra recrutar, pensei em gente como eu!". Cantando, pulando e dançando o tempo todo ao som de sua potente charanga, a Coligay embalava o time e os estádios por onde passava. 0 que realmente os distinguia era a animação e o bom humor.

0 clube acolheu a torcida e esta, além da alegria, trouxe sorte e foi pé quente! Logo, todos os gremistas puderam comemorar o mais festejado título gaúcho da história (1977) e seguiram comemorando, Brasileiro, Libertadores, até a conquista do mundo, em 1983.

A torcida chegou ao fim, pois seu líder, Volmar, retornou naquele ano para sua terra natal, Passo Fundo. Mas a Coligay já havia ajudado a colorir os anos de chumbo.

O Grêmio tem feito esforços para tentar transformar sua imagem bastante associada como um clube elitista e, mesmo, racista. Além do painel da Coligay e do torcedor negro Bombardão ${ }^{20}$ em seu museu, o clube passou a adotar a alcunha de "Clube de Todos" tentando associar uma nova imagem de clube plural e inclusivo.

Procuramos nos diálogos realizados identificar como a memória ou esquecimento sobre a torcida homossexual do Grêmio era entendida e narrada pelos torcedores do clube. ${ }^{21}$ Aqui nos interessou, especialmente, observar como a torcida homossexual poderia se relacionar com indivíduos torcedores isolados ou com o sujeito coletivo, torcida, nesse novo espaço e nesse novo tempo.

Em diferentes diálogos utilizamos a relação do Sport Club Internacional com os negros como mito de origem. O principal rival do Grêmio teve uma excelente capacidade de produção de sua vinculação ao popular e, também, aos negros a partir das décadas de 1930 e de 1940 e acaba sendo lido como um clube em que a presença negra se vincula a sua origem. Para os diálogos conseguimos trabalhar razoavelmente bem essa relação como 'mito de origem' do rival. Em um exercício de imaginação, questionamos esses mesmos torcedores para saber se

\footnotetext{
${ }^{20}$ Bombardão foi um torcedor ícone do clube entre as décadas de 1920 e 1950. Negro e pobre ele se destacava pelos gritos de Grêmio no Centro da cidade de Porto Alegre.

${ }^{21}$ Uma discussão mais aprofundada sobre como os torcedores dialogam com as memórias da Coligay podem ser encontradas em BANDEIRA; SEFFNER. Memórias da Coligay e o currículo de masculinidade dos torcedores de futebol.
} 
eles entendiam que seria possível o Grêmio realizar uma apropriação semelhante utilizando a Coligay como certo mito de origem para narrar sua história torcedora como mais tolerante. Ângelo 22 afirmou que "possível é, mas eu, particularmente não iria curtir a história do time ser em cima disso aí, não por um preconceito para mim não interessa se é negro, se é branco se é veado, mas... quer vir, vem" ${ }^{23}$ (DC 12). ${ }^{24}$ Edilson respondeu que "quando eu falo com algum outro torcedor esse é um assunto que não gostam como gremista. Se os caras pudessem apagar isso aí poderia passar despercebido, não é um título que a gente gostaria de ter como o primeiro clube a mostrar que não tem preconceito" (DC 21). É interessante que mesmo nesse contexto, Edilson acredita que não existe preconceito contra homossexuais na torcida do Grêmio: "beleza, não há preconceito, mas não precisa fazer uma torcida gay para isso" (DC 21). Essa relação entre a existência ou não de preconceito/violência em relação a torcedores homossexuais também é entendida dessa maneira pelos antigos integrantes da Coligay. Em seu trabalho sobre a torcida, Luiza Aguiar dos Anjos aponta: "Chama atenção o fato da existência de preconceito ser negada pelos ex-componentes da Coligay, mas ao mesmo tempo, de mencionarem situações em que não se sentiam seguros no ambiente futebolístico e o fato de tomarem certas precauções". ${ }^{25}$ Adilson achava muito difícil o Grêmio realizar tal apropriação: "eu acho que o clube não se apega tanto como o Inter fez, trouxe. O Grêmio quer se apegar como um clube que a torcida tanto homossexual, negro, branco, todos tenham seus direitos e tenham lugar no estádio sem nenhum preconceito" (DC 24). Jonas creditou a ação de colocar a torcida no Memorial a uma estratégia de marketing do clube: "foi uma jogada boa do marketing do Grêmio ter assumido e não fugir do assunto como fugia antigamente" (DC 25). Réver entendia que era bem difícil falar. Segundo ele, "o preconceito racista caiu, sei lá, de 100\%, deve ter 1\% de racismo no mundo, digamos assim.

\footnotetext{
${ }^{22}$ Os nomes dos torcedores com os quais dialogamos ao longo da estada em campo foram substituídos para manutenção do anonimato.

${ }^{23}$ As falas dos torcedores registradas com o gravador serão destacadas em itálico.

${ }^{24}$ Todas as manifestações dos torcedores compuseram nossos diários de campo. Optamos por utilizar após cada um desses trechos a sigla DC, para diário de campo, e o número do respectivo diário. Nossos diários foram construídos a partir das observações e dos diálogos realizados com os torcedores. Tentamos elucidar neles, especialmente, as relações entre as falas dos entrevistados, modos como os interpelamos e fomos interpelados por eles, além de relacionar suas falas com a teoria que dá suporte ao nosso trabalho.

${ }^{25}$ ANJOS. De "são bichas, mas são nossas" à "diversidade da alegria", p. 119.
} 
Agora, em relação aos gays, em relação ao orgulho do clube, eu não sei se o clube futuramente usaria como marketing do clube a parte da torcida gay" (DC 29). Enquanto gremista, ele acreditava que não faria essa positivação: “eu não tenho nada contra, eu até acho que são torcedores, assim como nós, que tem que participar, mas eu não sei se o clube usaria isso como marketing do clube, enfim, como orgulho" (DC 29).

Outra forma de relacionamento com a Coligay é ignorar a possibilidade de vivências torcedoras distintas. Colocando o 'gremismo' como marcador essencial da relação entre os diferentes torcedores, Hernán definiu: "se o cara torce pelo Grêmio e é apaixonado pelo Grêmio, eu não tenho preconceito nenhum, se a pessoa está ali independentemente da cor, da raça que ela tem e gosta do time não tem porque banir essas pessoas do estádio" (DC 7). Kléber disse: "a nossa parte, somos gremistas independentemente de cor, sexo, etnia, qualquer coisa. A gente está junto para empurrar o tricolor" (DC 7). Rhodolfo, em um exercício sobre a interpretação que poderia ser dada em um eventual retorno da Coligay, argumentou: "tu não tens a torcida gay do Grêmio, é uma torcida do Grêmio. Eles são gays, eles são brancos, eles são assados, ok, mas é uma torcida do Grêmio" (DC 11). Ele acreditava que as diferentes identidades são subsumidas ao 'gremismo' dentro do estádio: “lá fora eu tenho uma vida, tu tens uma vida, cada um tem sua vida, não vou eu julgar tua vida de acordo com o que eu acho que é certo ou não. Aqui dentro todo mundo é gremista, são grupos que vão se reunir para torcer a favor do Grêmio" (DC 11). Em alguma medida, uma torcida subordinada ao "torcer a favor do Grêmio", que disfarce ou ignore suas diferenças, poderia ser bem acolhida.

Sobre um eventual retorno da Coligay, Everaldo afirmou não ter nada contra, mas apontou outros atores como possíveis dificultadores desse retorno: "se quiserem criar o que forem criar, quem frequenta, quem é torcedor, se é homossexual ou não é, não tem diferença, mas eu acho que a torcida Geral do Grêmio ia criar alguma dificuldade, algum preconceito em relação a isso" (DC 12). Rodrigo entendia que, quando o livro foi lançado,"26 "o Grêmio tinha que ter abraçado essa história. Qualquer história ligada ao Grêmio é do Grêmio, faz parte do Grêmio" (DC 14). Victor acreditava que "existem gays nas torcidas de Grêmio e de Internacional, mas

${ }^{26}$ GERCHMANN. Coligay: tricolor e de todas as cores. 
eles não se apresentam como tal. Eu acredito que se um grupo de torcedores aparecesse com faixas e bandeiras de uma torcida gay eles seriam facilmente alvo de violência física” (DC 18). Sobre a possibilidade de um eventual retorno da Coligay, Germán argumentou: "eu apoiaria, gostaria, mas eu acho que a reação da torcida, por exemplo, aqui a reação da torcida do Grêmio para uma manifestação a favor da Coligay eu acho que seria reprimida. Iria receber uma opressão por parte da própria torcida" (DC 29). Sobre a possibilidade de uma torcida gay em qualquer estádio no Brasil, Renato disse: "teria a possibilidade, mas ela seria hostilizada, eu tenho certeza que sim, em qualquer clube, eu tenho certeza que sim" (DC 31).

\section{O CASO ARANHA E AS POSSIBILIDADES DE RESPONSABILIDADES INDIVIDUAIS E COLETIVAS}

Em 28 de agosto, Grêmio e Santos fizeram a primeira partida das oitavas de final da Copa do Brasil de 2014 na Arena do Grêmio, em Porto Alegre. Próximo ao final da partida, o goleiro Aranha, da equipe paulista, afirmou que torcedores do Grêmio posicionados na Arquibancada Inferior Norte (setor com ingressos mais baratos e destinado aos torcedores que assistem às partidas em pé e às torcidas organizadas) o chamaram de "preto fedido" e de "macaco", além imitarem sons emitidos por macacos em direção ao atleta.

O, então, assessor de futebol do clube gaúcho, Marcos Chitolina, defendeu punição aos torcedores, ao mesmo tempo em que procurou eximir o clube de responsabilidade: "Não vamos compactuar com o racismo, mas o Grêmio não pode ser punido por um ato individual. A administração da Arena tem todas as condições de buscar a identificação. Assim que for encontrado, vai punir e tomar as medidas necessárias". ${ }^{27} 0$ argumento de defesa do clube e de responsabilização individual dos diretamente envolvidos poderia ser pensado, exclusivamente, como uma tentativa de produzir ganho jurídico. Porém, é possível inserir essa argumentação em certo viés moral destacando desde o início que os violentos são os outros ou, no mínimo, isolar os protagonistas de determinados atos.

\footnotetext{
27 Disponível em: http://globoesporte.globo.com/futebol/times/gremio/noticia/2014/08/gremiodefende-punicao-torcedores-nao-vamos-compactuar-com-racismo.html. Acesso em 10/06/2020, às 11 h06.
} 
Uma imagem produzida pelo canal de televisão ESPN flagrou a torcedora Patrícia Moreira gritando o termo "macaco". Essa torcedora acabou sendo colocada como a principal responsável pelas ofensas dirigidas ao goleiro. A imagem da jovem e loira torcedora conseguiu personificar a injúria racial e acabou servindo como argumento para que o clube apresentasse a hipótese de que a ofensa se tratava de uma ação isolada. Se pensarmos, porém, que toda a fala é excitável, os falantes poderão alegar que não possuem a total responsabilidade pelo uso de uma linguagem que os precede e os excede. Neste caso, mesmo que a tentativa de isolar a atitude possa trazer algum conforto moral, essa opção acabaria por desconsiderar o contexto em que tal 'atitude individual' se originou. Como nos lembra Guacira Louro "quem insulta não insulta sozinho, mas é, de fato, um falante que ecoa outras vozes". 28

As novas arenas/estádios brasileiras construídas para a Copa do Mundo de 2014, ou seguindo as mesmas diretrizes sugeridas pelo Caderno de Encargos da FIFA, possuem um grande controle do público $^{29}$ na tentativa de individualizar suas ações em um processo que, em alguma medida, poderia ser comparado ao modelo do panóptico que, segundo Michel Foucault, "é uma máquina de dissociar o par ver-ser visto: no anel periférico, se é totalmente visto, sem nunca ver; na torre central, vê-se tudo, sem nunca ser visto". ${ }^{30}$ Richard Giulianotti lembra que o “controle panóptico do espaço público foi testado em 'condições normais', pela primeira vez, no campo de futebol". ${ }^{31}$ Essa vigilância se aplicaria ao conjunto de torcedores em suas individualidades. Com isso, esses sujeitos deixariam de ser entendidos como anônimos na multidão, o que algumas interpretações sugerem que produziria um sentimento de inimputabilidade em suas condutas. Essa 'novidade' das atuais arenas corresponde a um processo disciplinar dos torcedores. É uma forma de condução das condutas que tende a ser mais barata e eficiente, pois opera em uma autorregularão das ações. "Quem está submetido a um campo de visibilidade, e sabe disso, retoma por sua conta as limitações do

\footnotetext{
${ }^{28}$ LOURO. Discursos de ódio, p. 274.

${ }^{29}$ BANDEIRA; BECK. As novas arenas e as emoções dos torcedores dos velhos estádios.

${ }^{30}$ FOUCAULT. Vigiar e punir, p. 167.

${ }^{31}$ GIULIANOTTI. Sociologia do futebol: dimensões históricas e socioculturais do esporte das multidões, p. 111.
} 
poder na qual ele desempenha simultaneamente os dois papéis; torna-se o princípio de sua própria sujeição".32

A partir de Gilles Deleuze, se poderia ter outro entendimento e apontar que as práticas do estádio estariam mais vinculadas ao controle do que à disciplina. 0 autor recorda que as ações de controle são de curto prazo, contínuas e ilimitadas, enquanto a disciplina se fazia em processos de longa duração, de maneira infinita e descontínua.

Estamos entrando nas sociedades de controle que funcionam não mais por confinamento, mas por controle contínuo e comunicação instantânea. [...] 0 que está sendo implantado, às cegas, são novos tipos de sanções, de educação, de tratamento. [...] Pode-se prever que a educação será cada vez menos um meio fechado. ${ }^{33}$

O comentarista do canal Sportv, Maurício Noriega, destacava a multidão como um fator que poderia interferir no comportamento dos indivíduos gerando atitudes condenáveis: "Infelizmente, quando tem multidões, o cara até é um sujeito bacana, comportado, mas no meio de um monte de gente, ele se transforma e a idiotice prevalece. É lamentável que isso aconteça de novo". ${ }^{34}$ Esse processo que desloca o sujeito individual - torcedor - a integrante de uma determinada multidão - torcida - precisa ser aflorado e vai se construindo desde o caminho até o estádio. ${ }^{35} 0$ contexto das arenas e seu controle contínuo, em alguma medida, faria com que o indivíduo torcedor não mais pudesse ser parte de um coletivo ou de uma multidão, mas fosse continuamente individualizado, avaliado e responsabilizado por suas condutas, ignorando a construção de sociabilidades distintas, como a torcedora. Até então, se pensava na sociabilidade torcedora que iria se construindo desde o caminho até o estádio, e era possível imaginar que ela permaneceria após o encerramento da partida em algumas oportunidades. Esse processo de individualização constante captada pela tecnologia do novo estádio acaba estimulando algumas ações e emoções ao mesmo tempo em que restringe uma série de outras ações e emoções naturalizadas nas experiências torcedoras dos antigos estádios.

\footnotetext{
${ }^{32}$ FOUCAULT. Vigiar e punir, p. 168.

33 DELEUZE. A vida como obra de arte, p. 215-6.

${ }^{34}$ Disponível em: https://glo.bo/38MSgvO. Acesso em: 10 jun. 2020.

${ }^{35}$ DAMO. Futebol, engajamento e emoção.
} 
O processo de individualização dos sujeitos torcedores, como conseguimos visualizar nas atuais arenas, a partir dos assentos individuais e do monitoramento realizado pelas câmeras, pode ser pensado como uma tentativa de manter mais estáveis os marcadores identitários dos indivíduos dentro dos estádios. Isso poderia provocar uma diminuição das experiências de conjunto, ao mesmo tempo em que poderia facilitar o controle pelos organizadores dos eventos.

[...] el hecho de estar formando parte de una masa libera de las reglas de la vida ordinaria, por eso, por ejemplo, se puede decir malas palabras, $\mathrm{y}$ esto favorece la expansión de valores proscritos en lo cotidiano, se actualiza un sentimiento de comunidad que está desdibujando en la vida de todos los días. ${ }^{36}$

É do interior de um certo aparato tecnológico, aliado à arquitetura das novas arenas, que a produção de distintos modos de torcer se engendra, eventualmente tornando inaceitáveis atitudes que até pouco tempo eram corriqueiras.

Casos como o que envolveu o goleiro Aranha podem ser lidos como fazendo parte do jogo, nesse tempo diferente da vida cotidiana como entendido por Huizinga. ${ }^{37}$ Neste caso, as ofensas poderiam ser lidas como fazendo parte do contexto dos enfrentamentos. Hernán acreditava que os jogos possuem componentes específicos e poderiam ser entendidos como "um caso à parte, na adrenalina do jogo muita gente fala besteira, muita gente fala coisa que não deveria falar, mas eu acho que tu estás no estádio, tu tens liberdade para falar algumas coisas, tu ficas com raiva, assim como tu ficas feliz com algumas coisas" (DC 7). Everaldo entendeu que "a menina chamou o cara de macaco nas pilhas da torcida. Eu levo em consideração que ela estava nas pilhas da torcida e gritou e sem querer ofender" (DC 12). Ele acreditava que a manifestação, individualizada na figura da torcedora Patrícia Moreira, está dentro de um contexto mais amplo dos diversos xingamentos que aparecem nos estádios de futebol: "tu podes chamar o cara de macaco da mesma forma que tu chamas o outro de filho da puta ou de alguma coisa assim, mas tu sais do estádio e acabou, isso não existe mais. É aquele momento do jogo, a torcida pegando no pé" (DC 12). Adilson acreditava que os xingamentos aconteceram em um momento "de loucura, de estar acostumado, de calor do jogo"

\footnotetext{
${ }^{36}$ BROMBERGER. Significaciones de la pasión popular por los clubes de fútbol, p. 27.

${ }^{37}$ HUIZINGA. Homo Ludens.
} 
(DC 24). Maurício afirmou que o coletivo 'torcida' ofendeu o goleiro: “não foi uma pessoa, foi infelicidade da guria, eu acho que muitas pessoas chamaram sim, eu acho que foi uma infelicidade, foi na emoção. Uma emoção que deve sim, com certeza ser controlada, deve ser sim, banida do futebol" (DC 28). Para Patrício, o ocorrido no 'caso Aranha' "foi mais uma coisa do calor do momento. O Aranha vinha no decorrer do jogo fazendo muita cera, o Grêmio estava perdendo o jogo, então foi no calor do momento" (DC 33).

Um dos entendimentos dos torcedores sobre o ocorrido durante a partida de ida das oitavas de final da Copa do Brasil não negava o episódio racista. Entretanto, existia certa discordância dos procedimentos punitivos e, mesmo, da responsabilidade pelos atos ao clube ou a seu conjunto de torcedores. Rhodolfo afirmou: "vamos supor que a guria fosse racista. A guria era racista. Ela odeia negro. Ela vê um negro e começa a xingar. Cara, ela representa ela" (DC 11). Ele concluiu que "ela não representa a torcida do Grêmio, ela representa ela só, ponto. Aí tu taxares o time por causa da opinião de um torcedor, de dois ou até se fosse uma quantidade maior de torcedores, perto do que foi o estádio" (DC 11). Edilson acreditava ser difícil controlar as manifestações dos torcedores. Ele entendia, também, que "têm pessoas que pensam totalmente ao contrário uma das outras aqui e se pudéssemos controlar essas pessoas sem nenhuma pessoa se manifestar de forma que ofenda um jogador ou outra torcida assim se controlaria" (DC 21). Sobre a punição sancionada ao clube, Patrício afirmou: "é ridícula porque tu vais punir sete milhões de torcedores eliminando um time por causa de um ato de um torcedor, isso é completamente ridículo" (DC 33).

É bastante interessante pensar a partir de certos indicadores apontados pelos torcedores. A exigência de unanimidade poderia apontar para existências de discursos totalizadores dentro da torcida? A lógica da produção identitária 'gremista' teria algum tipo de traço capaz de igualar as ideias desse conjunto de torcedores? 0 que significa sermos sete milhões de gremistas? Em alguma medida, parece existir o entendimento da inexistência de consenso entre os torcedores, mas parece existir, também, um entendimento na direção contrária que apontaria para algo capaz de unir esses tais sete milhões de gremistas. Na fala de um dos torcedores, ele apontava que a torcedora representaria apenas a ela mesma. Isso 
poderia ser ampliado e cada torcedor ser apenas o representante de si mesmo? Se cada torcedor é um e suas ações são individuais e individualizadas, faz sentido falar em torcida enquanto sujeito coletivo?

\section{A RELAÇÃo ENTRE o TORCEDOR E A TORCIDA NA ARENA DO GRÊMIO}

Durante a abordagem aos sujeitos, realizamos um exercício para tentar nos aproximarmos de como os torcedores entendiam a presença da Coligay na história do torcer pelo Grêmio. Questionamos se os torcedores acreditavam ser possível a presença de uma torcida homossexual no Grêmio ou, mesmo, em outro clube do futebol brasileiro. Enquanto alguns torcedores mais sensibilizados às pautas de diferentes minorias apontavam que seria uma questão de tempo e que ocorreria naturalmente, outros marcavam que essa existência seria desnecessária ou equivocada. Segundo esse raciocínio, a torcida deveria unir e não separar. No caso da torcida do Grêmio, o único ingrediente que deveria ser levado em consideração seria o gremismo. Incentivando a equipe e colaborando com o clube, os torcedores homossexuais estariam autorizados a torcer 'conosco', mas sem a necessidade de uma torcida homossexual. Esse gremismo era lido nessa chave de inteligibilidade como não possuindo marcadores de masculinidade. Em alguma medida, o currículo de masculinidade dos torcedores de estádio foi bastante competente ao participar da construção de sujeitos generificados que não percebiam os diferentes processos pedagógicos pelos quais tiveram que percorrer para se constituírem enquanto torcedores.

As tecnologias de individualização dos torcedores acabam diminuindo as possibilidades do sujeito ser subsumido pela multidão. A multidão dava certo contorno aos sujeitos e, também, a torcida. Com essa modificação posta pelas novas praças esportivas, o próprio torcer pode ser modificado. A coletividade era um ingrediente importante da socialização torcedora nos antigos estádios. Acerca das sanções aplicadas ao clube após os episódios de injúria racial na Arena do Grêmio, alguns torcedores reclamaram que os indivíduos que se manifestaram de forma injuriosa deveriam ser responsabilizados individualmente, mas não o clube, pois essa punição seria injusta com a coletividade de torcedores. A tecnologia da 
Arena do Grêmio permite individualizar as ações dos torcedores por seus mecanismos de controle, o que poderia autorizar que o coletivo de torcedores fosse desfeito a qualquer momento e recriado novamente sem a presença de algum elemento 'indesejado'. Ao mesmo tempo, esse coletivo é solicitado para tentar acomodar um certo 'nós' gremistas, para reivindicarmos sermos vítimas de uma punição exagerada ou inadequada. A própria relação dos indivíduos torcedores com seus telefones e câmeras, que os mantém conectados com aqueles que estão distantes do estádio, poderia diminuir tanto a possibilidade de associação à coletividade dos demais presentes no estádio, como acabar exigindo que sua postura fosse avaliada por seus relacionamentos extra estádio de futebol, mesmo durante o tempo do jogo.

A relação entre o indivíduo torcedor e esse 'ente coletivo' que chamamos de torcida é uma chave explicativa para um número importante de atitudes. Os torcedores conseguem diferenciar-se desse coletivo, ao mesmo tempo em que se entendem participantes dessa mesma coletividade. A torcida, em algumas circunstâncias, não poderia ser responsabilizada por ações realizadas por individualidades torcedoras, ao mesmo tempo em que as individualidades torcedoras não poderiam ser adequadamente avaliadas em suas ações sem levar o contexto da torcida em consideração.

A diferenciação entre certo 'eu', torcedor, e 'ela', torcida, acabaria marcando boa parte dos entendimentos sobre liberdade e responsabilidade do que é dito dentro do estádio. Os torcedores afirmavam que boa parte das manifestações dentro do estádio acontecia nas "pilhas" ou no "calor da torcida". Essas afirmações apontavam que o indivíduo torcedor não teria domínio sobre aquilo que manifestava. Ao mesmo tempo, quando clube ou torcida fossem apontados como responsáveis por uma fala dita nesse contexto, imediatamente seria realizado um processo inverso. Nesse caso, esse indivíduo, que não seria autônomo para a construção de sua manifestação, precisaria ser responsabilizado individualmente, mesmo que essa individualidade só tivesse realizado tal manifestação por estar em meio ao coletivo de torcedores. 
Essa contradição explícita dialoga bastante bem com a ideia de clubismo. ${ }^{38}$ É possível inferir que as percepções ética, estética e moral são atravessadas por essa comunidade de sentimento. É através deste pertencimento que os indivíduos torcedores conseguem sentir as emoções de toda uma vida: felicidade, sofrimento, ódio, angústia, admiração e sentimento de injustiça. Um dos conteúdos do clubismo é a defesa incondicional da agremiação. 0 mesmo clubismo que ensina que o pertencimento pode alterar as ações dos torcedores também ensina que é necessário defender o clube, especialmente se existe algum risco de punições financeiras ou esportivas.

Na Arena do Grêmio também é possível observar pequenos conjuntos de torcedores agrupados com diferentes práticas em relação a outros setores do estádio, nas torcidas organizadas maiores ou na lógica das multidões. Aqui, o agrupamento é feito pelo time/clube, mas também por fatores outros, como vínculos políticos ou de visão de mundo e afetivos. Seria possível apontar que esses pequenos grupos poderiam trabalhar com uma lógica ampliada de relações familiares ou afetivas, que ainda parece ser a principal maneira como os torcedores se dirigem ao estádio, sejam em duplas de irmãos, pais e filhos, namorados etc. Na Arena existe a faixa de uma torcida de quatro pessoas integrantes de uma mesma família, por exemplo.

Não chegou a ser o objeto de discussão desse artigo, mas uma das alterações de público percebida pelos torcedores poderia estar mais bem associada ao entendimento de "familiarização". Mais do que uma massa de torcedores, os sujeitos entendiam que as famílias estavam ocupando o estádio. A família esteve muito associada às mulheres e às crianças. 0 maior conforto e as maiores possibilidades de escolhas de consumo para eleger um lugar no estádio acabavam facilitando a presença desses agentes agrupados no conceito de família. Essa família, nas falas dos torcedores, foi posta como oposição ao antigo frequentador, o torcedor que sem ser nomeado pode ser entendido como um homem jovem ou jovem adulto que estaria associado a uma estética vinculada ao popular, mais bem lida como uma estética com menores preocupações vinculadas

\footnotetext{
${ }^{38}$ DAMO. O espetáculo das identidades e das alteridades.
} 
a polidez. A família impõe um sobrenome e um lugar um tanto fixo na relação entre seus membros que a multidão ou o espaço público não sustentariam. Essa fixidez imposta pela família ajudaria a controlar a irrupção de comportamentos masculinos considerados destoantes para o bom andamento do espetáculo esportivo. Em alguma medida, a família dificultaria o ingresso dos indivíduos torcedores no sujeito coletivo torcida, diminuindo, com isso, as alterações de subjetivação dos indivíduos. Ela acaba funcionando como uma instância que poderia refrear os impulsos e ordenar os comportamentos de forma bastante ativa.

A elitização e a arquitetura do estádio, somados a outras tecnologias, permitem que o sujeito no meio da multidão seja mais facilmente individualizado. Isso acaba fazendo com que esse indivíduo tenha maiores dificuldades na transição entre o sujeito atravessado por diferentes currículos de subjetividade para o sujeito torcedor. Essa dificuldade para o sujeito torcedor, que precisaria responder afirmativamente à lógica de socialização do estádio, faz com que a ideia de coletividade seja um tanto borrada. Há uma fluidez maior entre torcedor e torcida. O torcedor, mesmo dentro da torcida, ao ser individualizado carrega consigo marcadores de raça/etnia, sexualidade, classe social, pertença familiar. Com isso, os compromissos éticos, políticos, estéticos e morais de fora do estádio não poderão ser deslocados mediante a interpelação do currículo do torcedor de estádio de futebol, ao menos não da forma como eram feitos anteriormente. Ainda é muito cedo para saber o que acontecerá com o que temos chamado de currículo de masculinidade dos torcedores de estádio a partir da desnaturalização de algumas práticas. Agora, mais do que antes, há um jogo a ser jogado sobre as construções dos torcedores e do torcer nos estádios de futebol.

\section{REFERÊNCIAS}

AMARAL, Rita. Festa como objeto e como conceito. In: Festa à brasileira: sentidos de festejar no país que não é sério. Tese de doutorado, São Paulo, PPGAS/USP, 2001. 
ANJOS, Luiza Aguiar do. De "são bichas, mas são nossas" à "diversidade da alegria": uma história da torcida Coligay. 2018. Doutorado. Programa de PósGraduação em Ciências do Movimento Humano, UFRGS, Porto Alegre, Brasil.

BANDEIRA, Gustavo Andrada. Uma história do torcer no presente: elitização, racismo e heterossexismo no currículo de masculinidade dos torcedores de futebol. Curitiba: Appris editora, 2019.

BANDEIRA, Gustavo Andrada; BECK, Matheus Passos. As novas arenas e as emoções dos torcedores dos velhos estádios. Esporte e Sociedade, n. 23, 2014, p. 1-12.

BANDEIRA, Gustavo Andrada; SEFFNER, Fernando. Memórias da Coligay e o currículo de masculinidade dos torcedores de futebol. Diversidade e Educação, v. 7, 2019, p. 312-328.

BANDEIRA, Gustavo Andrada; SEFFNER, Fernando. Aranha, macaco e veado: o legítimo e o não legítimo no zoológico linguístico nos estádios de futebol. Movimento, v. 22, n. 3, 2016, p. 985-998.

BROMBERGER, Christian. Significaciones de la pasión popular por los clubes de fútbol. Buenos Aires: Librosdel Rojas, 2001.

BUTLER, Judith. Relatar a si mesmo: crítica da violência ética. Belo Horizonte: Autêntica Editora, 2015.

DAMATTA, Roberto. A casa \& a rua: espaço, cidadania, mulher e morte no Brasil. Rio de Janeiro: Rocco, 5ª ed., 1997.

DAMO, Arlei Sander. Futebol, engajamento e emoção. In: HELAL, Ronaldo. AMARO, Fausto. Esporte e mídia: novas perspectivas - a influência da obra de Hans Ulrich Gumbrecht. Rio de Janeiro: EdUERJ, 2014a, p. 49-94.

DAMO, Arlei Sander. O espetáculo das identidades e das alteridades - as lutas pelo reconhecimento no espectro do clubismo brasileiro. In: CAMPOS, Flavio de; ALFONSI, Daniela. (Orgs.). Futebol objeto das ciências humanas. São Paulo: Leya, 2014b, p. 23-55.

DAMO, Arlei Sander. Do dom à profissão: uma etnografia do futebol de espetáculo a partir da formação de jogadores no Brasil e na França. Tese (Doutorado em Antropologia Social). Instituto de Filosofia e Ciências Humanas, Programa de Pós-Graduação em Antropologia Social, UFRGS, Porto Alegre, 2005.

DELEUZE, Gilles. A vida como obra de arte. In: Conversações. Rio de Janeiro: Ed. 34, 1992, p. 118-126.

ELIAS, Norbert. O processo civilizador II: formação do Estado e Civilização. Rio de Janeiro: Zahar, 1993.

FAUSTO, Boris. De alma lavada e coração pulsante. In: Revista de História. São Paulo: FFLCH/USP n. 163, 2010, p. 139-148.

FISCHER, Rosa Maria Bueno. Verdades em suspenso: Foucault e os perigos a enfrentar. In: COSTA, Marisa Vorraber. (Org.). Caminhos investigativos II: outros modos de pensar e fazer pesquisa em educação. Rio de Janeiro: DP\&A, 2002, p. 49-71. 
FOUCAULT, Michel. Vigiar e punir: nascimento da prisão. Petrópolis: Vozes, 2005. GERCHMANN, Léo. Coligay: tricolor e de todas as cores. Porto Alegre: Libretos, 2014.

GIULIANOTTI, Richard. Sociologia do futebol: dimensões históricas e socioculturais do esporte das multidões. São Paulo: Nova Alexandria, 2010.

GUEDES, Simoni Lahud. Os "europeus" do futebol brasileiro ou como a "pátria de chuteiras" enfrenta a ameaça do mercado. In: GASTALDO, Édison Luis; GUEDES, Simoni Lahud. (Orgs.). Nações em campo: Copa do Mundo e identidade nacional. Niterói: Intertexto, 2006, p. 73-85.

HUIZINGA, Johan. Homo Ludens. São Paulo, Perspectiva, 1993.

LOURO, Guacira Lopes. Discursos de ódio. In: SEFFNER, Fernando; CAETANO, Márcio. (Orgs.). Discurso, discursos e contra-discursos latinoamericanos sobre a diversidade sexual e de gênero. Rio Grande: Editora da FURG; Realize Editora, 2016, p. 271-282.

MEYER, Dagmar Estermann. Corpo, violência e educação: uma abordagem de gênero. In: JUNQUEIRA, Rogério Diniz. (Org.). Diversidade sexual na educação: problematizações sobre a homofobia nas escolas. Brasília: Ministério da Educação, Secretaria de Educação Continuada, Alfabetização e Diversidade, UNESCO, 2009, p. 213-233.

RUDÉ, George. A multidão na história: estudo dos movimentos populares na França e na Inglaterra 1730-1848. Rio de Janeiro: Campus, 1991.

TEIXEIRA, Rosana de Câmara. Futebol, emoção e sociabilidade: narrativas de fundadores e lideranças dos movimentos populares de torcedores no Rio de Janeiro. In: Esporte e Sociedade, n. 21, 2013, p. 1-16.

Recebido para publicação em: 14 jun. 2020. Aprovado em: 12 nov. 2020. 